\title{
Nanoparticle based insulin delivery system: the next generation efficient therapy for Type 1 diabetes
}

\author{
Garima Sharma ${ }^{1,2+}$, Ashish Ranjan Sharma ${ }^{1 \dagger}$, Ju-Suk Nam ${ }^{1 \dagger}$, George Priya C. Doss ${ }^{3}$, Sang-Soo Lee ${ }^{1 *}$ \\ and Chiranjib Chakraborty ${ }^{1,4^{*}}$
}

\begin{abstract}
Diabetic cases have increased rapidly in recent years throughout the world. Currently, for type-1 diabetes mellitus (T1DM), multiple daily insulin (MDI) injections is the most popular treatment throughout the world. At this juncture, researchers are trying to develop different insulin delivery systems, especially through oral and pulmonary route using nanocarrier based delivery system. This next generation efficient therapy for T1DM may help to improve the quality of life of diabetic patients who routinely employ insulin by the subcutaneous route. In this paper, we have depicted various next generation nanocarrier based insulin delivery systems such as chitosan-insulin nanoparticles, PLGA-insulin nanoparticles, dextran-insulin nanoparticles, polyalkylcyanoacrylated-insulin nanoparticles and solid lipid-insulin nanoparticles. Modulation of these insulin nanocarriers may lead to successful oral or pulmonary insulin nanoformulations in future clinical settings. Therefore, applications and limitations of these nanoparticles in delivering insulin to the targeted site have been thoroughly discussed.
\end{abstract}

Keywords: Nanocarrier, Insulin delivery, Type-1 diabetes mellitus (T1DM), Oral drug delivery, Pulmonary drug delivery

\section{Background}

Diabetes mellitus (hyperglycemia), a metabolic disorder, is caused either due to lower insulin secretion by the cells or due to lower binding efficiency of insulin on their cell surface receptors resulting in high blood glucose level. According to the survey in low- and middleincome countries there are 366 million people living with diabetes and the count is expected to rise to 552 million by 2030 [1]. Especially in the developing countries, diabetes has increased rapidly during the last decade. In 21st century, this diseases have the possibility to become a new epidemic in the Middle East, Sub-Saharan Africa, Latin America, India, and the rest of Asia [2]. Symptoms of diabetes include excessive weight loss, polyuria, polydipsia and polyphagia [3]. Diabetes has been categorized

\footnotetext{
*Correspondence: totalhip@hallym.ac.kr; drchiranjib@yahoo.com

${ }^{\dagger}$ Garima Sharma, Ashish Ranjan Sharma and Ju-Suk Nam contributed equally to this work

${ }^{1}$ Institute For Skeletal Aging, Hallym University-Chuncheon Sacred Heart

Hospital, Chuncheon 200704, Korea

Full list of author information is available at the end of the article
}

as Type 1 and Type 2 . Type 1 diabetes is insulin dependent condition, characterized by deficiency of insulin due to destruction of insulin-producing beta cells of islets of Langerhans by autoimmune system in pancreas. While, type 2 diabetes is distinguished as disorders of both insulin resistance and secretion due to defects in insulin receptor on cell membranes [4]. Besides these types of diabetes, gestational diabetes has also been reported in pregnant women. During pregnancy, abnormal hormonal production leads to woman's sensitivity to insulin resulting in high blood sugar levels [5].

Treatment of diabetes need constant monitoring of blood glucose level, regulating it through modified dietary sugar intake, physical exercise and insulin therapy (subcutaneous administration) to attain normoglycemia [6]. Disadvantages of subcutaneous administration of insulin are hypoglycemia [7], peripheral hyperinsulinemia [8], lipoatrophy, lipohyperatrophy [9], obesity due to intensive therapy [10], insulin neuropathy and insulin presbyopia. Current dosage of injectable insulin, required to maintain acceptable serum glucose level, comprise of 
up to four subcutaneous injections per day [11] which can cause psychological stress leading to poor patient compliance. Thus, focusing on the alternative route of administration (oral or pulmonary) or reducing the injection doses are beneficial to reduce the inconvenience and drawbacks associated with this conventional method [12-15]. Furthermore, orally delivered insulin reaches systemic circulation after passing through liver similar to physiological insulin secretion while injected insulin may result in peripheral hyperinsulinemia and associated complications. However, major obstructions in developing oral or pulmonary insulin formulations are either enzymatic barriers or physical barriers (i.e. intestinal epithelium), which oral insulin has to overcome [11, 16]. Insulin, 51 amino acid protein, can get deteriorated by gastric $\mathrm{pH}$ and intestinal enzymes, and even intestinal epithelial cell membranes serve as absorption barrier for intact peptide structure resulting in less than $1 \%$ bioavailabity of total insulin taken orally [17]. Taken together, restrictions like; fragile nature and short half-lives of proteins may serve as extra barriers in the formulation of oral dosage forms. In this context, over past few decades attempts have been made to develop suitable alternative formulations. Some of the methods include the use of permeation enhancers [18, 19]; protease inhibitors [20,21], hydrogels [22, 23], and protein-ligand conjugates $[24,25]$. Although, significant advancement has been made worldwide in attaining the general objective for a convenient and equally effective oral insulin delivery [15], still sufficient commercial development has not been achieved. As a solution to these challenges, nanocarriers have been considered as the best suited vehicle for oral delivery of insulin [26, 27]. Various nanocarriers, like polymeric or micelles, have granted a promising advancement to acquire desirable biopharmaceutical and pharmacokinetic properties for insulin. Therefore, in this review we have tried to highlight several nanocarrier formulations for insulin delivery related to chitosan coated nanoparticles, PLGA-insulin nanoparticles, dextraninsulin nanoparticles, PACA-insulin nanoparticles and solid lipid-insulin nanoparticles. Moreover, limitations associated with these nanocarriers for insulin delivery has also been discussed.

\section{Roles and possible mechanisms of nanocarriers in oral drug delivery system}

The bioavailability of orally delivered drugs is influenced by the physico-chemical properties of the drugs (i.e. solubility, pKa, size, etc.). The absorption of drugs and particles in gastrointestinal tract (GIT) occurs through various sites depending upon their size. Particles with $1 \mu \mathrm{m}$ diameter are absorbed via phagocytosis by intestinal macrophages while particles $<10 \mu \mathrm{m}$ in diameter are transported through peyer's patches (lymphatic islands present on GIT). Nanoparticles $(<200 \mathrm{~nm})$ are absorbed through endocytosis by enterocytes [28]. The efflux transporters such as P-glycoprotein (Pgp) and enzymes, expressed on enterocytes surface, also render the low systemic bioavailability of drugs affecting the absorption and excretion of drugs. [29]. Nanotechnology reveals the application of size scale complex systems in various fields due to their unique properties [30,31]. One of the extensively studied areas of nanotechnology is delivering systems for the active ingredient of the medicine. Effective nanomedicine must be stable, biodegradable, non-toxic, non-inflammatory, non-thrombogenic, nonimmunogenic and should escape by reticuloendothelial system [32, 33]. Moreover, nanomedicine should be applicable to different molecules such as small drugs, proteins, vaccines or nucleic acids [34]. It has been proved experimentally that, for therapeutic and imaging applications, nanoparticles may range from 2 to $1000 \mathrm{~nm}$ [35]. Additionally, nanotechnology offers the wide range of advantages to the drug delivery field including oral drug delivery in particular, i.e., increase efficacy, tolerability, specificity and therapeutic index of analogous drugs [36]. Furthermore, for oral delivery of drugs nanotechnology may assist in the delivery of poorly water-soluble drugs, transcytosis of drugs across the tight intestinal barrier, targeting of drugs to the specific part of the gastrointestinal tract and in the intracellular and transcellular delivery of bulky macromolecules [37]. Also, to facilitate the oral absorption of peptides and proteins, nanocarriers can be modified with specific ligands and targeted to the receptors on epithelial cell surface [22, 38-41]. Among various limitations of oral delivery of certain drugs is their poor absorption from the GIT. Such limitations can be overcome by the use of bioadhesive polymers which can facilitate the adhesion of nanocarrier to the mucosal epithelial membrane and can assist in nanoparticle uptake [42]. Other than the oral delivery of drugs using nanocarriers, pulmonary means of delivery is also an efficient route (Fig. 1).

The use of biodegradable polymeric nanoparticles have evolved as a better alternative for oral/pulmonary delivery of proteins and peptide drugs [43]. Furthermore, the stability and functional abilities of the nanoparticles can be modulated by some of the pharmaceutically accepted excipients able to regulate $\mathrm{pH}$ responsivity and Pgp effect e.g. cyclodextrin, chitosan, PLGA, TPGS/Vitamin E TPGS, etc. [44]. Lowman et al. (1999) formulated $\mathrm{pH}$ sensitive nanocarriers to overcome the limitations of oral insulin delivery and observed decrease in blood glucose level for longer time $(8 \mathrm{~h})$ in diabetic rats at a dose of $25 \mathrm{IU} / \mathrm{kg}$ of loaded insulin [17]. In addition, the controlled release of encapsulated insulin and its enhances uptake and bioavailability can also be modulated by the 


\section{Oral Insulin Delivery Route using Nanocarrier}

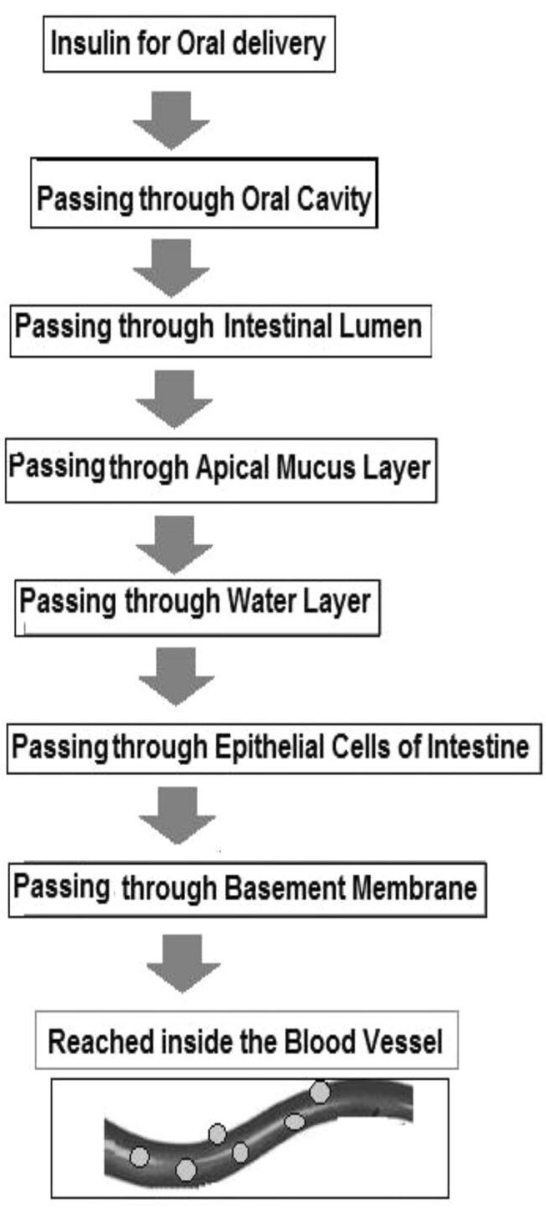

Pulmonary Insulin Delivery Route using Nanocarris

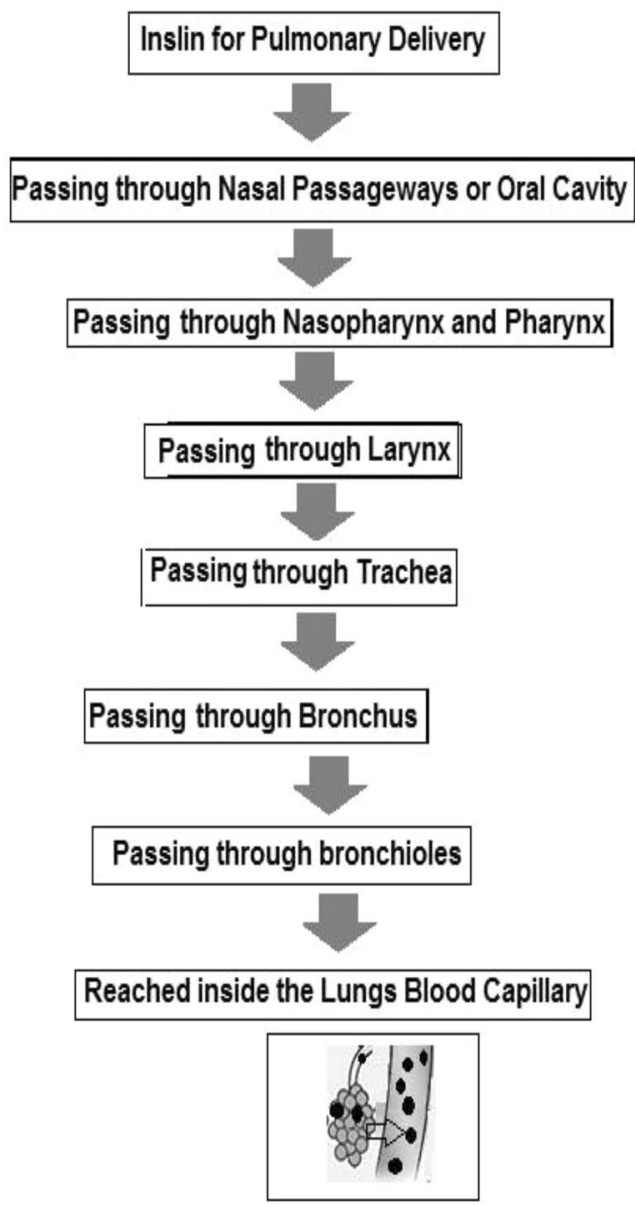

Fig. 1 Major two routes of nanocarrier based insulin delivery

use of various combinations of polymers and targeted molecules [34, 45]. Some of the $\mathrm{pH}$ sensitive biodegradable polymers explored so far are PMAA [46], HPMCP (HP55) [47], dextran sulphate [48], alginate [48], PGA [49] etc.

\section{Nanocarriers based insulin delivery}

Due to the drawbacks of conventional injectable insulin, drugs have been modified through nanocarriers with targeting ligands for their selective and targeted delivery meant for oral and pulmonary delivery [22, 41]. Different nanoparticles developed to form stable and efficient insulin delivery system (Fig. 2) are discussed below.

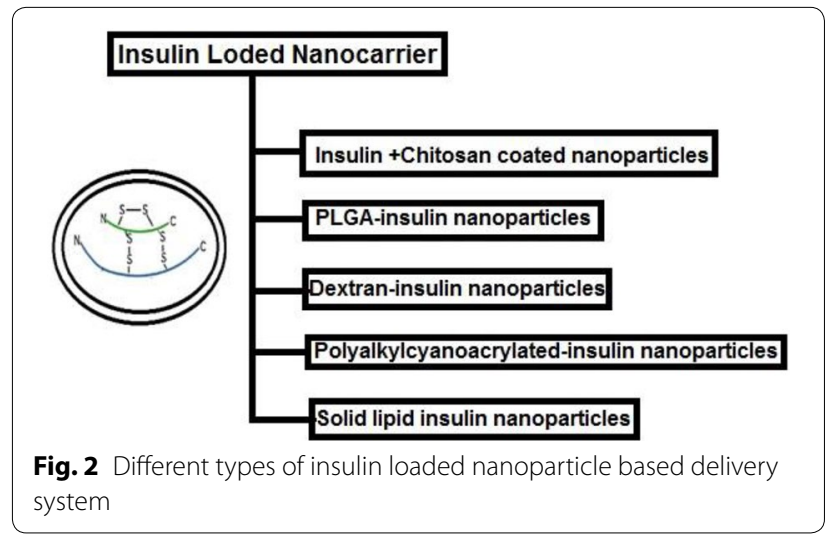




\section{Chitosan coated nanoparticles}

Chitosan is a linear polysaccharide, composed of $\beta$-(1-4)linked D-glucosamine and $N$-acetyl-D-glucosamine. The hydrophilic drugs, like insulin, cannot diffuse across epithelial cells as the intestinal epithelium is a major barrier for their absorption. So, it is difficult for them to enter the bloodstream [16]. Therefore, transport of hydrophilic drugs via paracellular pathways has been studied in detail [27]. Nevertheless, the presence of tight junctions at the luminal aspect of adjacent epithelial cells restricts the transport of hydrophilic drug through paracellular pathway [50-53]. Chitosan is a nontoxic cationic polysaccharide which has been used as the permeation enhancer for the absorption of hydrophilic molecules [54-57]. Chitosan adheres to the mucosal surface and opens up the tight junction between epithelial cells [58-60]. The expression of Claudin-4, a transmembrane protein responsible for tight junction integrity, is Chitosan mediated [61]. Thus, advances in developing stable and efficient chitosan-based particulate insulin delivery system have been examined [60, 62, 63]. Enhanced permeation of chitosan-insulin nanoparticles, synthesized by ionic gelation method using tripolyphosphate sodium (TPP) or poly(acrylic acid) (PAA), has been reported [64]. Further, Lin et al. (2007), showed that chitosan-insulin nanoparticles prolong the residence time of insulin in the small intestine and enhance the permeation of insulin via paracellular pathway to the blood stream. TEM micrographs showed mechanistic details that the chitosan can reversible open tight junctions between Caco- 2 cells which increased paracellular permeability [65]. Chitosaninsulin nanoparticles infiltrate into the mucus layer and transiently open the tight junctions located between epithelial cells. In turn, these nanoparticles have become unstable due to $\mathrm{pH}$ sensitivity and degrade releasing encapsulated insulin [66]. Chitosan-insulin nanoparticles have also been studied for their significant adsorption characteristics via nasal route of administration [67, 68]. These nanoparticles were synthesized by ionotropic gelation of chitosan and insulin loading was mediated by ionic interaction mechanism. Polyelectrolyte complexation method was also used for insulin loaded chitosan/ alginate nanoparticles and showed their internalization through intestinal mucosa [69-71]. Jelvehgari et al., used complex coacervation method for nanoparticles formation of $199 \mathrm{~nm}$ diameter using Eudragit L100-55 and chitosan of various molecular weights with $3.38 \%$ entrapment and $30.56 \%$ insulin loading efficiency [72]. The polyelectrolyte complexes of chitosan and insulin gets easily dissociated in acidic medium of the stomach and released insulin resulted in low pharmacological availability due to degradation by enzymatic activity in the GIT [64]. In order to modulate the rate of insulin delivery from chitosan/alginate nanoparticles, magnetite nanoparticles were synthesized inside chitosan/alginate matrix by coprecipitation method for subcutaneous implant approach [73]. Further, oral insulin formulation was prepared by combining nanoencapsulation and lipid emulsion [74]. These microemulsions prevented insulin from enzymatic degradation and enhanced their bioavailability [75, 76]. Cui et al. [77] improved the oral efficiency of insulin by encapsulating it in the shell of $\mathrm{pH}$ sensitive carboxylated chitosan grafted poly(methyl methacrylated) nanoparticles via hydrogen bonding, electrostatic interaction and van der waals forces. These nanoparticles exhibited $\mathrm{pH}$ sensitive property with slow release at pH 2.0 and quick release at $\mathrm{pH} 6.8$ and 7.4. Sarmento et al. constructed dextran sulfate and chitosan nanoparticles in varying ratios for entrapping insulin, and showed their efficiency as oral insulin delivery nanoparticulate system $[78,79]$.

\section{PLGA-insulin nanoparticles}

PLGA is FDA approved biodegradable synthetic polymer used frequently for drug delivery. Using computational analysis, Lassalla et al. showed the presence of hydrophobic and hydrophilic interactions between insulin and PLGA polymer [80]. PLGA nanoparticles were formulated by a modified solvent diffusion technique as model nanocarriers for insulin and potential oral drug delivery system [81-83]. Insulin loaded PLGA (PNP) and PLGA-Hp55 nanoparticles (PHNP) nanoparticles were also investigated as an effective method of reducing serum glucose levels, in vivo. The relative bioavailability of PNP and PHNP compared with subcutaneous (s.c.) injection $(1 \mathrm{IU} / \mathrm{kg})$ in diabetic rats observed was $3.68 \pm 0.29$ and $6.27 \pm 0.42 \%$, respectively [47]. Hp55 was used as a pH sensitive cellulose coating to resist high acidic $\mathrm{pH}$ of gastric fluids for longer time simultaneously dissolving in lower acidic $\mathrm{pH}$ of small intestine. Double emulsion solvent evaporation method was also used to design PLGA encapsulated insulin nanoparticles and then embedded within PVA hydrogels. This composite system showed a reduction in both the release rate and the total amount of insulin released [84]. Attempts have been made to modify the slight negative surface charge of PLGA by using polycationic polymer, chitosan. Because of the positive surface charge, chitosan reverses the effect of negative charge on PLGA further supporting endocytosis of nanoparticles through their increased interaction with the cell membrane [85]. Previously, chitosan has been known as one of the Pgp modulator which may decrease the Pgp-mediated efflux of drug loaded nanoparticles from the luminal surface of cells [86]. As a result, chitosan modified PLGA nanoparticles exhibited strong bioadhesive potency and increased 
pharmacological availability with regard to orally delivered insulin [87]. PLGA nanoparticles harbouring insulin-S.O (sodium oleate) complex was prepared via an emulsion solvent diffusion method and was evaluated for their pharmacological effects via oral administration to diabetic rats [88]. It was seen that, after $12 \mathrm{~h}$ of administration, plasma glucose level was reduced to $23.85 \%$ from the initial level, and this conditioned was maintained till 24 h. S.O is an anionic surfactant which forms an ionic complex with positively charged insulin at suitable $\mathrm{pH}$ and improves the apparent liposolubility of insulin. Additionally, the structure of polymers used to fabricate drug loaded nanoparticles can also impact their functional properties. Thus, in another method bovine insulin was entrapped in linear PLGA-PEG, star-branched $\beta$-cyclodextrin-PLGA ( $\beta$-CD-PLGA), and glucose-PLGA (Glu-PLGA) copolymeric nanoparticles using double emulsion method to enhance the complexation between insulin and polymers for their sustained release for $24 \mathrm{~h}$ [89]. Such kind of approach can provide single oral dose which could eliminate the need for repeated insulin doses till $24 \mathrm{~h}$. In a similar study, folate (FA) coupled PEG-PLGA nanoparticles were used to encapsulate insulin by solvent evaporation method and showed that once-daily administration would be sufficient to control diabetes for at least $24 \mathrm{~h}$ [90].

\section{Dextran-insulin nanoparticles}

Earlier studies suggest that the best way to treat diabetes is to provide exogenous insulin level according to the blood glucose level of the patient [91]. Although the methods described above enhance insulin delivery process, still their release mechanism is not proportional to the required physiological blood sugar concentration. To achieve the goal of glucose responsive release of insulin, the researchers have focused on novel nanomaterials. Among these approaches, competitive binding is the most acceptable one [92-95]. Synthesizing nanoparticles with such glucose responsive materials would carry the advantages of nanosized particles as well as glucose response dependent release of insulin in the body.

Zion et al. (2003), synthesized a novel reverse microemulsion (RM) mediated glucose-responsive dextran, $\operatorname{poly}(\alpha-1,6$ glucose $)$, nanoparticles which was physically crosslinked with the tetrafunctional glucose-binding protein, Concanavalin A (Con A), for controlled insulin delivery [96]. Upon contact with free glucose, Con A releases polymeric glucose and further binds to free glucose, leading to disintegration of hydrogel. As discussed above, insulin is marginally stable and can easily break up during their formulation as drugs [97]. Therefore, in order to achieve stable insulin formulation, aqueous insulin encapsulating nanoparticle delivery system was developed. This method utilized oppositely charged dextran sulfate (DS) and polyethylenimine (PEI) along with zinc as a stabilizer and was tested for insulin stability. However, this system showed no significant conformational changes in encapsulated insulin as compared to free insulin [98]. Recently, for oral delivery of peptides the use of some natural uptake processes of the intestine like vitamin B12 (VB12) transport system has also been highlighted which utilizes VB12-IF-IFR (intrinsic factor receptor) mediated endocytosis through intestinal ileocytes for targeting systemic circulation [99-101].

VB12-dextran NPs conjugates, chemically coupling insulin, acting as an oral delivery system has also been attempted to protect insulin against gut proteases and to show a faster release profile $[41,102]$. These nanoparticle conjugates were found to be viable carrier for personal insulin delivery to treat diabetes. A multilayered nanoparticle system consisting of mucoadhesive polymers, sodium alginate and dextran sulfate, around calcium was also developed to entrap insulin which enhances the residence time at absorption site. This system was further stabilized by chitosan bound to ploxamer 188 further coated with albumin A to protect insulin from enzymatic degradation. This nanoformulation of insulin exerted an efficient and persistent hypoglycemic effect in diabetic rats [103]. In a similar study, Reis et al., synthesized mucoadhesive, biodegradable, biocompatible and acid protected the sodium alginate and dextran sulfate nanospheres, having insulin in their core. Additionally, these nanospheres were coated with chitosan, BSA and PEG 4000 [104].

\section{Polyalkylcyanoacrylated-insulin nanoparticles}

Initially, PACA were used as a tissue glue [105] in surgery because of their stable and biodegradable character [106]. Recently, it has been utilized in the transportation of insulin through intestinal epithelium polymeric insulin carrier for oral administration [107]. According to MALDI ionization coupled tandem time-of-flight (TOF) mass spectrometry analysis, insulin was not modified during covalent bonding with PACA nanoparticles [108]. Entrapment of insulin in PACA nanoparticles prepared from microemulsions with the different microstructure containing isopropyl myristate, caprylocaproyl macro golglycerides, polyglyceryl oleate and insulin solution were investigated for in vitro release and bioactivity [109]. Moreover, insulin-loaded polybutylcyanoacrylate nanoparticles (IPN) were also tried for the hypoglycemic effect upon oral administration to streptozotocin (STZ) induced diabetic rats in an oily medium (soybean oil containing $0.5 \%(\mathrm{v} / \mathrm{v})$ Tween-20 and $5 \%(\mathrm{v} / \mathrm{v})$ Vitamin E). It was concluded that IPN can serve as an effective and stable delivery system for oral insulin [110]. 


\section{Solid lipid insulin nanoparticles}

As an alternative to polymeric nanoparticles, solid lipid nanoparticles (SLN) were developed for drug delivery nanoparticulate system [111]. SLN is sub micron, around $50-1000 \mathrm{~nm}$ in diameter, colloidal carriers made up of lipids which are solid at room temperature. SLN can be dispersed in water or surfactant solution [112]. Advantages of SLN as nanoparticle carrier systems are biodegradability [111], increased bioavailability, extended blood residence time [113], high tolerability [114] and easy large scale commercial production $[113,115,116]$. Moreover, SLN can be taken up by the lymphoid tissues in the peyer's patches. Oral administration of lectin modified SLNs with loaded insulin demonstrated declined enzymatic degradation and enhanced oral absorption [117]. It is well known that lectins consist of a diverse class of proteins having the capability to bind specific carbohydrates. Since, many proteins and lipids of GIT membrane are glycosylated, these lectins render a suitable alternative for recognition and enhanced uptake of drug loaded nanocarriers by intestinal mucosal membrane. In vivo hypoglycemic effect of SLN containing insulin, synthesized by solvent emulsification evaporation method, was studied for $24 \mathrm{~h}$, and it was seen that SLN can encourage the oral absorption of insulin. This method was based on a w/o/w emulsion technique [115]. Insulin mixed micelle loaded SLNs was prepared with reverse micelle double emulsion method using the mixture of stearic acid and palmitic acid. The liposolubility of insulin was improved by using sodium cholate and soybean phosphatidylcholine. This insulin delivery system had an excellent long term stability at $4{ }^{\circ} \mathrm{C}$ [118]. Octaarginine is an arginine rich derivative which is known as cell penetrating peptide assisting in uptake of various drug carriers. Zhang et al. 2009 attempted octaarginine modified SLN as oral insulin delivery system [119]. Internalization of above mentioned insulin-SLN by Caco- 2 cells was increased by 18.44 folds as compared to insulin solution [120]. Furthermore, researches focused on coating SLN with chitosan. Mainly due to the fact that non-coated SLN were shown to be uptaken by RAW 264.7 cell lines, whereas chitosan coated SLN were not internalized by this macrophage cell line. This may be due the fact that the addition of stealth layer on SLN by chitosan may enable SLN to escape phagocytosis [121]. Another such approach was carried out to produce insulin entrapped chitosan-coated Witepsol 85E SLNs. At first, solvent emulsificationevaporation method based on a water/oil/water double emulsion method was used to produce SLN, followed by chitosan coating on SLN surface. This work too showed enhanced permeation of chitosan coated SLN in comparison to noncoated SLN [122]. Studies were also performed to find out suitable lipid materials to synthesize insulin loaded SLN, and it was seen that glyceryl palmitostearate was the best suited lipid in terms of hydrophobicity, lower burst release and high pharmacological availability [123]. Besides oral delivery, SLNs was also used for pulmonary delivery of insulin. In this method, both cationic and anionic insulin-SLN nanoparticles were prepared and were then allowed to self assembled into flocculates due to electrostatic interactions. Finally, the flocculates were lyophilized to form dry powder for pulmonary administration [124].

\section{Other targeted nanoparticles encapsulating insulin}

Targeted ligand modified nanocarriers were proposed earlier to facilitate the oral absorption of proteins and peptides [38]. Some of the reported targeting agents to enterocytes or $\mathrm{M}$ cells are lectins, transferrin and vitamin B12 [22, 39-41]. However, the targeting effect of these ligands can be hindered by the presence of the mucus layer on the epithelium $[125,126]$. Therefore, more efficient targeting and highly specific ligands need to be explored which can overcome the mucus barrier on epithelium. Lately, a peptide was identified which have an affinity with goblet cells. Goblet cells consist of the second largest population of cells in intestinal epithelia. This peptide, CSKSSDYQC, was identified from phage-peptide library using in vivo phage display method [127]. Reports suggested enhanced uptake of CSKSSDYQC modified insulin containing chitosan nanoparticles in villi and increased permeation of insulin across the goblet cell-like HT29-MTX cells through clathrin and caveolae mediated endocytosis [26]. Recently, transportation of insulin loaded nanoparticles to neonatal Fc receptor $\left(\mathrm{FcRn}_{\mathrm{C}}\right)$ across intestinal epithelium was studied [128]. FcRn are expressed on epithelial cells and assists in IgG transport through them by binding to Fc region of the antibodies in a $\mathrm{pH}$ dependent manner. Therefore, the transportation of various nanoparticles to FcRn can be facilitated by the use of Fc region of IgG as a targeting ligand.

\section{Limitations}

Although attempts have been made so far in the development of oral insulin nanoparticulate (Table 1), the formulation and synthesis of more efficient nanoformulation is required for commercial significance. Recently, a number of insulin nanocarriers have undergone clinical trials among which many of them faced failure. Drawbacks associated with them include toxicology, low level of oral bioavailability and elevated intraindividual difference in insulin absorption. In the near future, to develop clinically significant insulin loaded nanocarriers biocompatibility, biodegradability and immunological responses should be considered. As a result, various features have to 


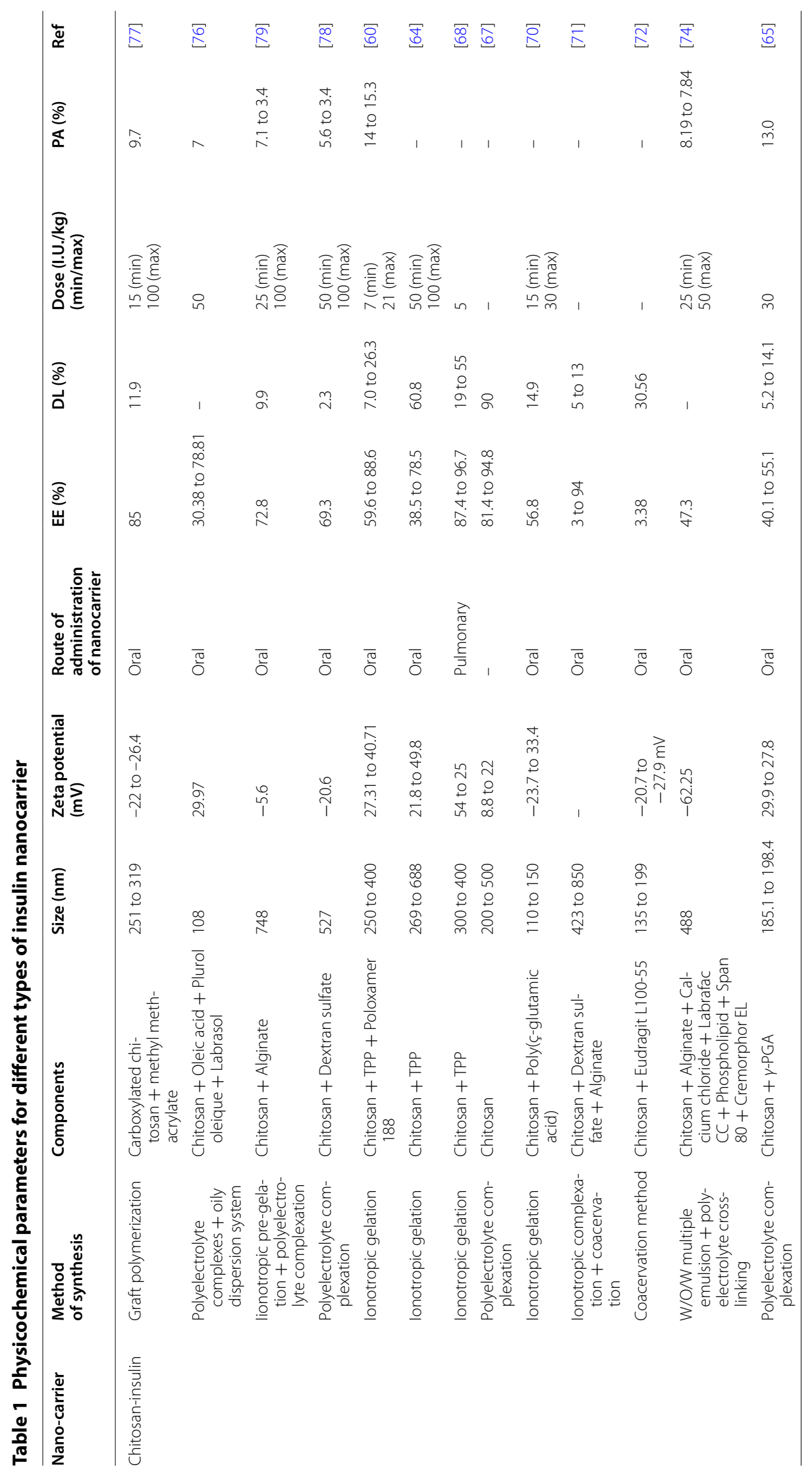




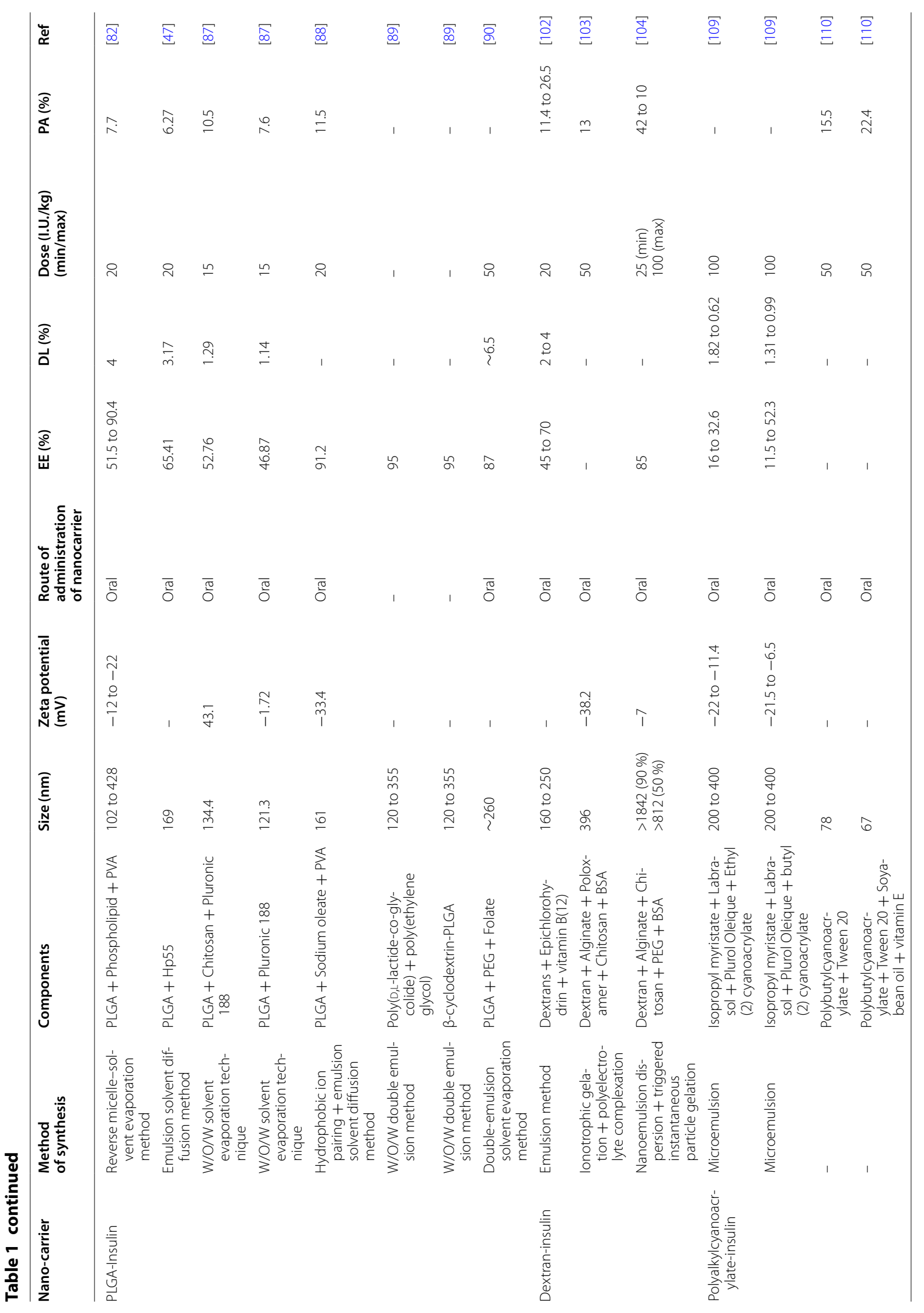




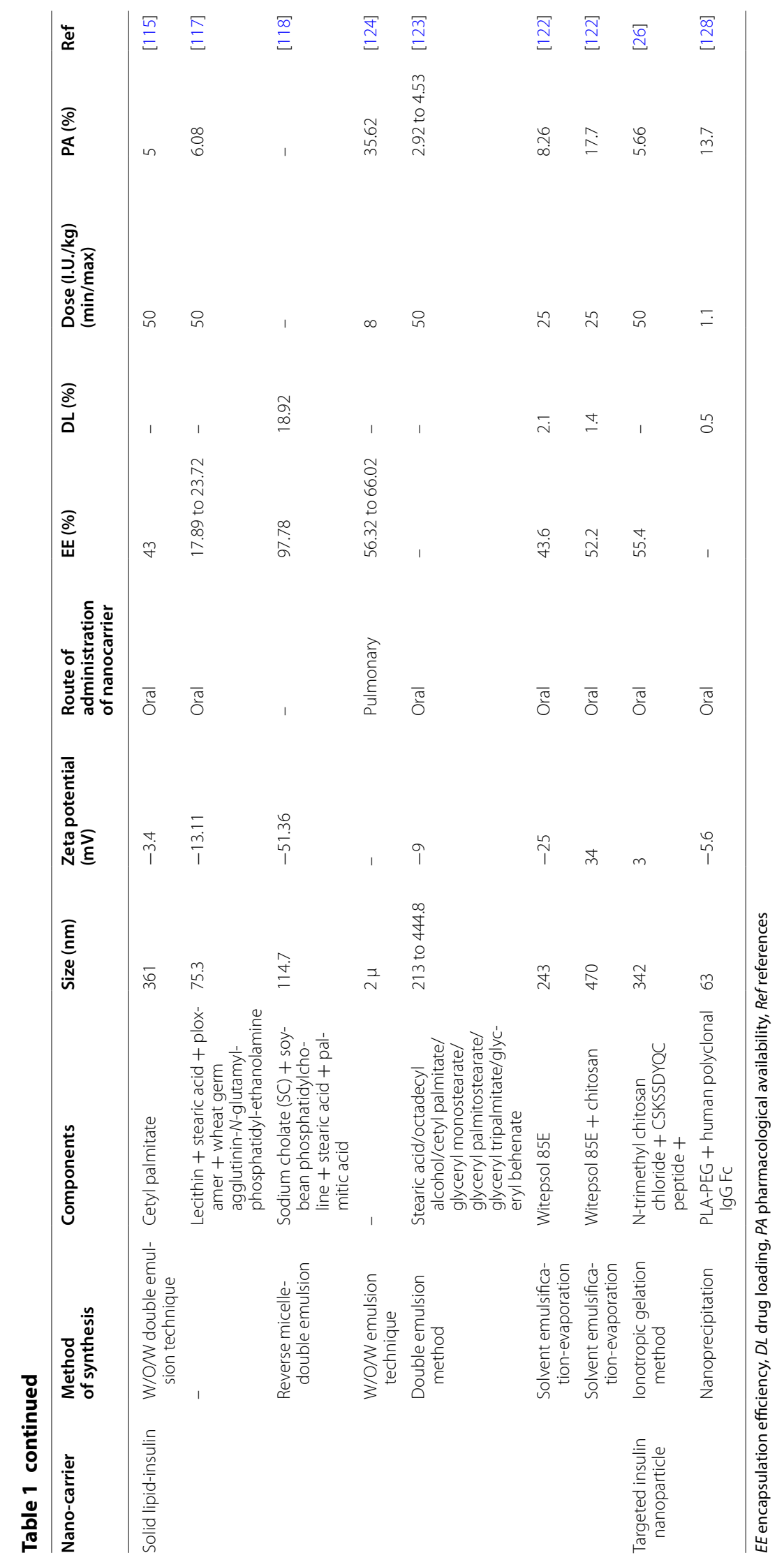


be taken in account before designing novel insulin nanocarriers. Some of the features are optimum particle size which can interact with the intestinal mucosa, the stability of the nanocarriers in biological fluids after in vivo administration, surface chemical composition, internal chemical composition and use of targeting ligands specific for apical membrane receptors. Additionally, detailed study about distribution kinetics and the interaction of nanocarriers with the mucosal lining of intestinal epithelia is also needed.

\section{Conclusion}

Presently, nanoparticle based drug delivery system are playing an essential role in the pharmaceutical industry. A new drug delivery system of an existing drug can provide a new marketability which is the important in the economic point of view. The next generation nanoparticles based insulin may be the future medicine for T1DM. In the near future, this nanocarrier based insulin delivery could replace the traditional and most predictable subcutaneous insulin injections. Possibly this next generation nanoparticle mediated insulin may improve efficacy of this medicine and will also help the better quality of the living of T1DM patients.

\begin{abstract}
Abbreviations
PLGA: Poly(lactic-co-glycolic acid); PACA: Poly(alkylcyanoacrylate); TPGS: D-atocopheryl polyethylene glycol 1000 succinate; PMAA: Poly(methacrylic acid); HPMCP: Hydroxypropyl methylcellulose phthalate; PGA: Poly glutamic acid; FDA: Food and drug administration; PVA: Polyvinyl alcohol; PEG: Polyethylene glycol; BSA: Bovine serum albumin; MALDI: Matrix-assisted laser desorption ionization.
\end{abstract}

\section{Authors' contributions}

CC and SSL gathered the data. GS, JSN and ARS analysed it and wrote the review article. GPDC edited the article. All authors read and approved the final manuscript.

\section{Author details \\ ${ }^{1}$ Institute For Skeletal Aging, Hallym University-Chuncheon Sacred Heart Hospital, Chuncheon 200704, Korea. ${ }^{2}$ Amity Institute of Nanotechnology, Amity University, Noida, Uttar Pradesh, India. ${ }^{3}$ Medical Biotechnology Division, School of Biosciences and Technology, VIT University, Vellore 632014, Tamil Nadu, India. ${ }^{4}$ Department of Bio-informatics, School of Computer and Infor- mation Sciences, Galgotias University, Greater Noida, India.}

\section{Acknowledgements}

This study was supported by Hallym University Research Fund and a Grant of the Korean Health Technology R\&D Project, Ministry of Health \& Welfare, Republic of Korea (HI12C1265). The authors also take this opportunity to thank the management of VIT and Galgotias University for providing the facilities and encouragement to carry out this work.

\section{Competing interests}

The authors declare that they have no competing interests.

Received: 9 June 2015 Accepted: 15 October 2015

Published online: 24 October 2015

\section{References}

1. Whiting DR, Guariguata L, Weil C, Shaw J. IDF diabetes atlas: global estimates of the prevalence of diabetes for 2011 and 2030. Diabetes Res Clin Pract. 2011;94(3):311-21. doi:10.1016/j.diabres.2011.10.029.

2. Chakraborty C, Roy SS, Hsu MJ, Agoramoorthy G. Landscape mapping of functional proteins in insulin signal transduction and insulin resistance: a network-based protein-protein interaction analysis. PLoS One. 2011;6(1):e16388. doi:10.1371/journal.pone.0016388.

3. Kuzuya T, Nakagawa S, Satoh J, Kanazawa Y, Iwamoto Y, Kobayashi M et al. Report of the Committee on the classification and diagnostic criteria of diabetes mellitus. Diabetes Res Clin Pract. 2002;55(1):65-85. ([pii]: S0168822701003655).

4. Owens DR, Zinman B, Bolli GB. Insulins today and beyond. Lancet. 2001;358(9283):739-46. doi:10.1016/S0140-6736(01)05842-1.

5. Bener A, Saleh NM, Al-Hamaq A. Prevalence of gestational diabetes and associated maternal and neonatal complications in a fast-developing community: global comparisons. Int J Womens Health. 2011;3:367-73. doi:10.2147/IJWH.S26094jwh-3-367.

6. Standards of medical care in diabetes. Diabetes Care. 2013;36(Suppl 1):S11-S66. doi:10.2337/dc13-S011.

7. Hypoglycemia: a pitfall of insulin therapy. West J Med 1983;139(5):688-95.

8. Kennedy FP. Recent developments in insulin delivery techniques. Current status and future potential. Drugs. 1991:42(2):213-27.

9. Monaco L, Geffken G, Silverstein JH. Accuracy of injection site identification among children with insulin dependent diabetes mellitus: a comparison of traditional and new visual aids. Clin Pediatr (Phila). 1996;35(4):191-7.

10. Carlson MG, Campbell PJ. Intensive insulin therapy and weight gain in IDDM. Diabetes. 1993;42(12):1700-7.

11. Carino GP, Jacob JS, Mathiowitz E. Nanosphere based oral insulin delivery. J Control Release. 2000;65(1-2):261-9 ([pii]: S0168-3659(99)00247-3).

12. The effect of intensive treatment of diabetes on the development and progression of long-term complications in insulin-dependent diabetes mellitus. The Diabetes Control and Complications Trial Research Group. N Engl J Med. 1993;329(14):977-86. doi:10.1056/ NEJM199309303291401.

13. Hinchcliffe M, Illum L. Intranasal insulin delivery and therapy. Adv Drug Deliv Rev. 1999;35(2-3):199-234. ([pii]: S0169-409X(98)00073-8)

14. Stanley SA, Gagner JE, Damanpour S, Yoshida M, Dordick JS, Friedman JM. Radio-wave heating of iron oxide nanoparticles can regulate plasma glucose in mice. Science. 2012;336(6081):604-8. doi:10.1126/ science. 1216753.

15. Khan Ghilzai NM. New developments in insulin delivery. Drug Dev Ind Pharm. 2003;29(3):253-65. doi:10.1081/DDC-120018199.

16. Borchard G, Lueßen HL, de Boer AG, Verhoef JC, Lehr CM, Junginger HE. The potential of mucoadhesive polymers in enhancing intestinal peptide drug absorption. III: effects of chitosan-glutamate and carbomer on epithelial tight junctions in vitro. J Control Release. 1996;39(23):131-8. doi:10.1016/0168-3659(95)00146-8.

17. Lowman AM, Morishita M, Kajita M, Nagai T, Peppas NA. Oral delivery of insulin using $\mathrm{pH}$-responsive complexation gels. J Pharm Sci. 1999;88(9):933-7. doi:10.1021/js980337n.

18. Fasano A, Uzzau S. Modulation of intestinal tight junctions by Zonula occludens toxin permits enteral administration of insulin and other macromolecules in an animal model. J Clin Invest. 1997;99(6):1158-64. doi:10.1172/JCl119271.

19. Uchida T, Toida Y, Sakakibara S, Miyanaga Y, Tanaka H, Nishikata M, et al Preparation and characterization of insulin-loaded acrylic hydrogels containing absorption enhancers. Chem Pharm Bull (Tokyo). 2001:49(10):1261-6.

20. Yamamoto A, Taniguchi T, Rikyuu K, Tsuji T, Fujita T, Murakami M, et al. Effects of various protease inhibitors on the intestinal absorption and degradation of insulin in rats. Pharm Res. 1994;11(10):1496-500.

21. Marschutz MK, Caliceti P, Bernkop-Schnurch A. Design and in vivo evaluation of an oral delivery system for insulin. Pharm Res. 2000;17(12):1468-74.

22. Kavimandan NJ, Losi E, Peppas NA. Novel delivery system based on complexation hydrogels as delivery vehicles for 
insulin-transferrin conjugates. Biomaterials. 2006;27(20):3846-54. doi:10.1016/j.biomaterials.2006.02.026.

23. Musabayane CT, Munjeri O, Bwititi P, Osim EE. Orally administered, insulin-loaded amidated pectin hydrogel beads sustain plasma concentrations of insulin in streptozotocin-diabetic rats. J Endocrinol. 2000;164(1):1-6. ([pii]: JOE03436)

24. Gordon Still J. Development of oral insulin: progress and current status. Diabetes Metab Res Rev. 2002;18(Suppl 1):S29-37. doi:10.1002/ dmrr.207.

25. Xia CQ, Wang J, Shen WC. Hypoglycemic effect of insulin-transferrin conjugate in streptozotocin-induced diabetic rats. J Pharmacol Exp Ther. 2000;295(2):594-600.

26. Jin Y, Song Y, Zhu X, Zhou D, Chen C, Zhang Z, et al. Goblet cell-targeting nanoparticles for oral insulin delivery and the influence of mucus on insulin transport. Biomaterials. 2012;33(5):1573-82. doi:10.1016/j. biomaterials.2011.10.075.

27. Kotzé AF, Lueßen HL, de Leeuw BJ, de Boer BG. Coos Verhoef J, Junginger HE. Comparison of the effect of different chitosan salts and $\mathrm{N}$-trimethyl chitosan chloride on the permeability of intestinal epithelial cells (Caco-2). J Control Release. 1998;51(1):35-46. doi:10.1016/ S0168-3659(97)00154-5.

28. O'Hagan DT. The intestinal uptake of particles and the implications for drug and antigen delivery. J Anat. 1996;189(Pt 3):477-82.

29. Varma MV, Ashokraj Y, Dey CS, Panchagnula R. P-glycoprotein inhibitors and their screening: a perspective from bioavailability enhancement. Pharmacol Res. 2003;48(4):347-59.

30. Singhal G, Bhavesh R, Kasariya K, Sharma A, Singh R. Biosynthesis of silver nanoparticles using Ocimum sanctum (Tulsi) leaf extract and screening its antimicrobial activity. J Nanopart Res. 2011;13(7):2981-8. doi:10.1007/s11051-010-0193-y.

31. Singhal G, Bhavesh R, Sharma AR, Singh RP. ecofriendly biosynthesis of gold nanoparticles using medicianally important Ocimum basilicum leaf extract. Adv Sci Eng Med. 2012:4(1):62-6.

32. Kumari A, Yadav SK, Yadav SC. Biodegradable polymeric nanoparticles based drug delivery systems. Colloids Surf B Biointerfaces. 2010;75(1):118. doi:10.1016/j.colsurfb.2009.09.001.

33. Chakraborty C, Pal S, Doss GP, Wen ZH, Lin CS. Nanoparticles as 'smart' pharmaceutical delivery. Front Biosci (Landmark Ed). 2013;18:10301050. ([pii]: 4161).

34. des Rieux A, Fievez V, Garinot M, Schneider YJ, Preat V. Nanoparticles as potential oral delivery systems of proteins and vaccines: a mechanistic approach. J Control Release. 2006;116(1):1-27. doi:10.1016/j. jconrel.2006.08.013.

35. Singh R, Lillard JW Jr. Nanoparticle-based targeted drug delivery. Exp Mol Pathol. 2009;86(3):215-23. doi:10.1016/j.yexmp.2008.12.004.

36. Hall JB, Dobrovolskaia MA, Patri AK, MCNeil SE. Characterization of nanoparticles for therapeutics. Nanomedicine (Lond). 2007;2(6):789-803. doi:10.2217/17435889.2.6.789.

37. Farokhzad OC, Langer R. Impact of nanotechnology on drug delivery. ACS Nano. 2009;3(1):16-20. doi:10.1021/nn900002m10.1021/ nn900002m.

38. Roger E, Lagarce F, Garcion E, Benoit JP. Biopharmaceutical parameters to consider in order to alter the fate of nanocarriers after oral delivery. Nanomedicine (Lond). 2010;5(2):287-306. doi:10.2217/nnm.09.110.

39. Vandamme K, Melkebeek V, Cox E, Deforce D, Lenoir J, Adriaens E, et al. Influence of reaction medium during synthesis of Gantrez AN 119 nanoparticles for oral vaccination. Eur J Pharm Biopharm. 2010;74(2):202-8. doi:10.1016/j.ejpb.2009.10.001

40. Lochner N, Pittner F, Wirth M, Gabor F. Wheat germ agglutinin binds to the epidermal growth factor receptor of artificial Caco-2 membranes as detected by silver nanoparticle enhanced fluorescence. Pharm Res. 2003;20(5):833-9.

41. Chalasani KB, Russell-Jones GJ, Jain AK, Diwan PV, Jain SK. Effective oral delivery of insulin in animal models using vitamin B12-coated dextran nanoparticles. J Control Release. 2007;122(2):141-50. doi:10.1016/j. jconrel.2007.05.019.

42. Jung T, Kamm W, Breitenbach A, Kaiserling E, Xiao JX, Kissel T. Biodegradable nanoparticles for oral delivery of peptides: is there a role for polymers to affect mucosal uptake? Eur J Pharm Biopharm. 2000;50(1):147-60. doi:10.1016/S0939-6411(00)00084-9.
43. Florence AT. The oral absorption of micro- and nanoparticulates: neither exceptional nor unusual. Pharm Res. 1997;14(3):259-66.

44. Guo M, Rong WT, Hou J, Wang DF, LuY, Wang Y, et al. Mechanisms of chitosan-coated poly(lactic-co-glycolic acid) nanoparticles for improving oral absorption of 7-ethyl-10-hydroxycamptothecin. Nanotechnology. 2013;24(24):245101. doi:10.1088/0957-4484/24/24/245101.

45. Damge C, Reis CP, Maincent P. Nanoparticle strategies for the oral delivery of insulin. Expert Opin Drug Deliv. 2008;5(1):45-68. doi:10.1517/17425247.5.1.45.

46. Sajeesh S, Sharma CP. Cyclodextrin-insulin complex encapsulated polymethacrylic acid based nanoparticles for oral insulin delivery. Int J Pharm. 2006;325(1-2):147-54. doi:10.1016/j.jpharm.2006.06.019.

47. Cui FD, Tao AJ, Cun DM, Zhang LQ, Shi K. Preparation of insulin loaded PLGA-Hp55 nanoparticles for oral delivery. J Pharm Sci. 2007;96(2):4217. doi:10.1002/jps.20750.

48. Reis CP, Ribeiro AJ, Houng S, Veiga F, Neufeld RJ. Nanoparticulate delivery system for insulin: design, characterization and in vitro/ in vivo bioactivity. Eur J Pharm Sci. 2007;30(5):392-7. doi:10.1016/j. ejps.2006.12.007.

49. Sonaje K, Lin YH, Juang JH, Wey SP, Chen CT, Sung HW. In vivo evaluation of safety and efficacy of self-assembled nanoparticles for oral insulin delivery. Biomaterials. 2009;30(12):2329-39. doi:10.1016/j. biomaterials.2008.12.066.

50. Ballard ST, Hunter JH, Taylor AE. Regulation of tight-junction permeability during nutrient absorption across the intestinal epithelium. Annu Rev Nutr. 1995;15:35-55. doi:10.1146/annurev.nu.15.070195.000343.

51. Cereijido M, Shoshani L, Contreras RG. Molecular physiology and pathophysiology of tight junctions. I. Biogenesis of tight junctions and epithelial polarity. Am J Physiol Gastrointest Liver Physiol. 2000;279(3):G477-82.

52. Yamamoto T, Harada N, Kano K, Taya S, Canaani E, Matsuura Y, et al. The Ras target AF-6 interacts with ZO-1 and serves as a peripheral component of tight junctions in epithelial cells. J Cell Biol. 1997;139(3):785-95.

53. Furuse M, Itoh M, Hirase T, Nagafuchi A, Yonemura S, Tsukita S. Direct association of occludin with ZO-1 and its possible involvement in the localization of occludin at tight junctions. J Cell Biol. 1994;127(6 Pt 1):1617-26.

54. Ward PD, Tippin TK, Thakker DR. Enhancing paracellular permeability by modulating epithelial tight junctions. Pharm Sci Technolo Today. 2000;3(10):346-358 ([pii]: S1461534700003023)

55. Jin J, Song M, Hourston DJ. Novel chitosan-based films cross-linked by genipin with improved physical properties. Biomacromolecules. 2004;5(1):162-8. doi:10.1021/bm034286m.

56. Roy K, Mao HQ, Huang SK, Leong KW. Oral gene delivery with chitosanDNA nanoparticles generates immunologic protection in a murine model of peanut allergy. Nat Med. 1999;5(4):387-91. doi:10.1038/7385.

57. Ding Y, Xia XH, Zhang C. Synthesis of metallic nanoparticles protected with N, N, N-trimethyl chitosan chloride via a relatively weak affinity. Nanotechnology. 2006;17(16):4156-62. doi:10.1088/0957-4484/17/16/027.

58. Prego C, Fabre M, Torres D, Alonso MJ. Efficacy and mechanism of action of chitosan nanocapsules for oral peptide delivery. Pharm Res. 2006;23(3):549-56. doi:10.1007/s11095-006-9570-8.

59. Pan Y, Li YJ, Zhao HY, Zheng JM, Xu H, Wei G, et al. Bioadhesive polysaccharide in protein delivery system: chitosan nanoparticles improve the intestinal absorption of insulin in vivo. Int J Pharm. 2002;249(1-2):139347 ([pii]: S0378517302004866).

60. Takeuchi H, Thongborisute J, Matsui Y, Sugihara H, Yamamoto H, Kawashima Y. Novel mucoadhesion tests for polymers and polymercoated particles to design optimal mucoadhesive drug delivery systems. Adv Drug Deliv Rev. 2005;57(11):1583-94. doi:10.1016/j. addr.2005.07.008.

61. Tsukita S, Furuse M, Itoh M. Multifunctional strands in tight junctions. Nat Rev Mol Cell Biol. 2001;2(4):285-93. doi:10.1038/3506708835067088.

62. Agnihotri SA, Mallikarjuna NN, Aminabhavi TM. Recent advances on chitosan-based micro- and nanoparticles in drug delivery. J Control Release. 2004;100(1):5-28. doi:10.1016/j.jconrel.2004.08.010.

63. Prego C, Garcia M, Torres D, Alonso MJ. Transmucosal macromolecular drug delivery. J Control Release. 2005;101(1-3):151-62. doi:10.1016/j. jconrel.2004.07.030. 
64. Ma Z, Lim TM, Lim LY. Pharmacological activity of peroral chitosaninsulin nanoparticles in diabetic rats. Int J Pharm. 2005;293(1-2):271-80. doi:10.1016/j.ijpharm.2004.12.025.

65. Lin YH, Chen CT, Liang HF, Kulkarni AR, Lee PW, Singara Chen $\mathrm{CH}$, Sung HW. Novel nanoparticles for oral insulin delivery via the paracellular pathway. Nanotechnol. 2007;18.

66. Sung HW, Sonaje K, Liao ZX, Hsu LW, Chuang EY. pH-responsive nanoparticles shelled with chitosan for oral delivery of insulin: from mechanism to therapeutic applications. Acc Chem Res. 2012;45(4):619-29. doi:10.1021/ar200234q.

67. Mao S, Bakowsky U, Jintapattanakit A, Kissel T. Self-assembled polyelectrolyte nanocomplexes between chitosan derivatives and insulin. J Pharm Sci. 2006;95(5):1035-48. doi:10.1002/jps.20520.

68. Fernandez-Urrusuno R, Calvo P, Remunan-Lopez C, Vila-Jato JL, Alonso MJ. Enhancement of nasal absorption of insulin using chitosan nanoparticles. Pharm Res. 1999;16(10):1576-81.

69. Nam J-P, Choi C, Jang M-K, Jeong Y-I, Nah J-W, Kim S-H, et al. Insulin-incorporated chitosan nanoparticles based on polyelectrolyte complex formation. Macromol Res. 2010;18(7):630-5. doi:10.1007/s13233-010-0714-7.

70. Lin YH, Mi FL, Chen CT, Chang WC, Peng SF, Liang HF, et al. Preparation and characterization of nanoparticles shelled with chitosan for oral insulin delivery. Biomacromolecules. 2007;8(1):146-52. doi:10.1021/bm0607776.

71. Sarmento B, Martins S, Ribeiro A, Veiga F, Neufeld R, Ferreira D. Development and comparison of different nanoparticulate polyelectrolyte complexes as insulin carriers. Int J Pept Res Ther. 2006;12(2):131-8.

72. Jelvehgari M, Zakeri-Milani P, Siahi-Shadbad MR, Loveymi BD, Nokhodchi A, Azari Z, et al. Development of pH-sensitive insulin nanoparticles using Eudragit L100-55 and chitosan with different molecular weights. AAPS PharmSciTech. 2010;11(3):1237-42. doi:10.1208/ s12249-010-9488-7.

73. Finotelli PV, Da Silva D, Sola-Penna M, Rossi AM, Farina M, Andrade LR, et al. Microcapsules of alginate/chitosan containing magnetic nanoparticles for controlled release of insulin. Colloids Surf B. 2010;81(1):206-11. doi:10.1016/j.colsurfb.2010.07.008.

74. Li X, Qi J, Xie Y, Zhang X, Hu S, Xu Y, et al. Nanoemulsions coated with alginate/chitosan as oral insulin delivery systems: preparation, characterization, and hypoglycemic effect in rats. Int J Nanomed. 2013;8:2332. doi:10.2147/IJN.S38507ijn-8-023.

75. Cilek A, Celebi N, Tirnaksiz F, Tay A. A lecithin-based microemulsion of rh-insulin with aprotinin for oral administration: investigation of hypoglycemic effects in non-diabetic and STZ-induced diabetic rats. Int J Pharm. 2005;298(1):176-85. doi:10.1016/j.ijpharm.2005.04.016.

76. Elsayed A, Remawi MA, Qinna N, Farouk A, Badwan A. Formulation and characterization of an oily-based system for oral delivery of insulin. Eur J Pharm Biopharm. 2009;73(2):269-79. doi:10.1016/j.ejpb.2009.06.004.

77. Cui F, Qian F, Zhao Z, Yin L, Tang C, Yin C. Preparation, characterization, and oral delivery of insulin loaded carboxylated chitosan grafted poly(methyl methacrylate) nanoparticles. Biomacromolecules. 2009;10(5):1253-8. doi:10.1021/bm900035u.

78. Sarmento B, Ribeiro A, Veiga F, Ferreira D, Neufeld R. Oral bioavailability of insulin contained in polysaccharide nanoparticles. Biomacromolecules. 2007:8(10):3054-60. doi:10.1021/bm0703923.

79. Sarmento B, Ribeiro A, Veiga F, Sampaio P, Neufeld R, Ferreira D. Alginate/chitosan nanoparticles are effective for oral insulin delivery. Pharm Res. 2007;24(12):2198-206. doi:10.1007/s11095-007-9367-4.

80. Lassalle V, Ferreira ML. PLGA based drug delivery systems (DDS) for the sustained release of insulin: insight into the protein/polyester interactions and the insulin release behavior. J Chem Technol Biotechnol. 2010;85(12):1588-96. doi:10.1002/jctb.2470

81. Santander-Ortega MJ, Bastos-Gonzalez D, Ortega-Vinuesa JL, Alonso MJ. Insulin-loaded PLGA nanoparticles for oral administration: an in vitro physico-chemical characterization. J Biomed Nanotechnol. 2009;5(1):45-53.

82. Cui F, Shi K, Zhang L, Tao A, Kawashima Y. Biodegradable nanoparticles loaded with insulin-phospholipid complex for oral delivery: preparation, in vitro characterization and in vivo evaluation. J Control Release. 2006;114(2):242-50. doi:10.1016/j.jconrel.2006.05.013.

83. Han $Y$, Tian H, He P, Chen $X$, Jing X. Insulin nanoparticle preparation and encapsulation into poly(lactic-co-glycolic acid) microspheres by using an anhydrous system. Int J Pharm. 2009;378(1-2):159-66. doi:10.1016/j. ijpharm.2009.05.021.
84. Liu J, Zhang SM, Chen PP, Cheng L, Zhou W, Tang WX, et al. Controlled release of insulin from PLGA nanoparticles embedded within PVA hydrogels. J Mater Sci Mater Med. 2007;18(11):2205-10. doi:10.1007/ s10856-007-3010-0.

85. Tahara K, Sakai T, Yamamoto H, Takeuchi H, Hirashima N, Kawashima Y. Improved cellular uptake of chitosan-modified PLGA nanospheres by A549 cells. Int J Pharm. 2009;382(1-2):198-204. doi:10.1016/j. ijpharm.2009.07.023.

86. Bansal T, Jaggi M, Khar RK, Talegaonkar S. Emerging significance of flavonoids as P-glycoprotein inhibitors in cancer chemotherapy. J Pharm Pharm Sci. 2009;12(1):46-78.

87. Zhang X, Sun M, Zheng A, Cao D, Bi Y, Sun J. Preparation and characterization of insulin-loaded bioadhesive PLGA nanoparticles for oral administration. Eur J Pharm Sci. 2012;45(5):632-8. doi:10.1016/j. ejps.2012.01.002.

88. Sun S, Liang N, Piao H, Yamamoto H, Kawashima Y, Cui F. Insulin-S.O (sodium oleate) complex-loaded PLGA nanoparticles: formulation, characterization and in vivo evaluation. J Microencapsul. 2010;27(6):471-8. doi:10.3109/02652040903515490.

89. Davaran S, Omidi Y, Rashidi Mohammad Reza, Anzabi M, Shayanfar A, Ghyasvand S, et al. Preparation and in vitro Evaluation of Linear and Star-branched PLGA Nanoparticles for Insulin Delivery. J Bioactive Compat Polym. 2008;23(2):115-31. doi:10.1177/0883911507088276.

90. Jain S, Rathi W, Jain AK, Das M, Godugu C. Folate-decorated PLGA nanoparticles as a rationally designed vehicle for the oral delivery of insulin. Nanomedicine. 2012;7(9):1311-37. doi:10.2217/nnm.12.31.

91. Brownlee M, Cerami A. A glucose-controlled insulin-delivery system: semisynthetic insulin bound to lectin. Science. 1979;206(4423):1190-1. doi:10.1126/science.505005.

92. Miyata T, Uragami T, Nakamae K. Biomolecule-sensitive hydrogels. Adv Drug Deliv Rev. 2002;54(1):79-98. doi:10.1016/S0169-409X(01)00241-1.

93. Kost J, Langer R. Responsive polymeric delivery systems. Adv Drug Deliv Rev. 2001;46(1-3):125-48. doi:10.1016/S0169-409X(00)00136-8.

94. Obaidat AA, Park K. Characterization of protein release through glucose-sensitive hydrogel membranes. Biomaterials. 1997;18(11):801-6. doi:10.1016/S0142-9612(96)00198-6.

95. Tanna S, Sahota T, Clark J, Taylor MJ. A covalently stabilised glucose responsive gel formulation with a Carbopol ${ }^{\circledR}$ carrier. J Drug Target. 2002;10(5):411-8. doi:10.1080/1061186021000001869.

96. Zion TC. Glucose-sensitive nanoparticles for controlled insulin delivery. 2003.

97. Sluzky V, Tamada JA, Klibanov AM, Langer R. Kinetics of insulin aggregation in aqueous solutions upon agitation in the presence of hydrophobic surfaces. Proc Natl Acad Sci USA. 1991;88(21):9377-81.

98. Tiyaboonchai W, Woiszwillo J, Sims RC, Middaugh CR. Insulin containing polyethylenimine-dextran sulfate nanoparticles. Int J Pharm. 2003;255(1-2):139-51. doi:10.1016/S0378-5173(03)00055-3.

99. Russell-Jones GJ. Use of targeting agents to increase uptake and localization of drugs to the intestinal epithelium. J Drug Target. 2004;12(2):113-23. doi:10.1080/10611860410001693760.

100. Russell-Jones GJ, Westwood SW, Farnworth PG, Findlay JK, Burger HG. Synthesis of LHRH antagonists suitable for oral administration via the vitamin B12 uptake system. Bioconjug Chem. 1995;6(1):34-42.

101. Russell-Jones GJ, Westwood SW, Habberfield AD. Vitamin B12 mediated oral delivery systems for granulocyte-colony stimulating factor and erythropoietin. Bioconjug Chem. 1995;6(4):459-65.

102. Chalasani KB, Russell-Jones GJ, Yandrapu SK, Diwan PV, Jain SK. A novel vitamin B12-nanosphere conjugate carrier system for peroral delivery of insulin. J Control Release. 2007;117(3):421-9. doi:10.1016/j. jconrel.2006.12.003.

103. Woitiski CB, Neufeld RJ, Veiga F, Carvalho RA, Figueiredo IV. Pharmacological effect of orally delivered insulin facilitated by multilayered stable nanoparticles. Eur J Pharm Sci. 2010;41(3-4):556-63. doi:10.1016/j. ejps.2010.08.009.

104. Reis CP, Veiga FJ, Ribeiro AJ, Neufeld RJ, Damge C. Nanoparticulate biopolymers deliver insulin orally eliciting pharmacological response. J Pharm Sci. 2008;97(12):5290-305. doi:10.1002/jps.21347.

105. Woodward SC, Herrmann JB, Cameron JL, Brandes G, Pulaski EJ, Leonard F. Histotoxicity of cyanoacrylate tissue adhesive in the rat. Ann Surg. 1965;162:113-22. 
106. Lenaerts V, Couvreur P, Christiaens-Leyh D, Joiris E, Roland M, Rollman $B$, et al. Degradation of poly (isobutyl cyanoacrylate) nanoparticles. Biomaterials. 1984;5(2):65-8.

107. Damge C, Michel C, Aprahamian M, Couvreur P. New approach for ora administration of insulin with polyalkylcyanoacrylate nanocapsules as drug carrier. Diabetes. 1988;37(2):246-51.

108. Kafka AP, Kleffmann T, Rades T, McDowell A. Characterization of peptide polymer interactions in poly(alkylcyanoacrylate) nanoparticles: a mass spectrometric approach. Curr Drug Deliv. 2010. ([pii]: BSP-CDD-

\section{EPUB-00042)}

109. Graf A, Rades T, Hook SM. Oral insulin delivery using nanoparticles based on microemulsions with different structure-types: optimisation and in vivo evaluation. Eur J Pharm Sci. 2009;37(1):53-61.

110. Hou ZQ, Zhang ZX, Xu ZH, Zhang H, Tong ZF, Leng YS. The stability of insulin-loaded polybutylcyanoacrylate nanoparticles in an oily medium and the hypoglycemic effect in diabetic rats. Yao Xue Xue Bao. 2005;40(1):57-64

111. Müller RH, Rühl D, Runge SA. Biodegradation of solid lipid nanoparticles as a function of lipase incubation time. Int J Pharm. 1996;144(1):115-21. doi:10.1016/S0378-5173(96)04731-X.

112. Rawat $M$, Singh $D$, Saraf S. Nanocarriers: promising vehicle for bioactive drugs. Biol Pharm Bull. 2006;29(9):1790-1798. ([pii]: JST.JSTAGE/ bpb/29.1790)

113. Garcia-Fuentes M, Prego C, Torres D, Alonso MJ. A comparative study of the potential of solid triglyceride nanostructures coated with chitosan or poly(ethylene glycol) as carriers for oral calcitonin delivery. Eur J Pharm Sci. 2005;25(1):133-43. doi:10.1016/j.ejps.2005.02.008.

114. Müller RH, Maaßen S, Weyhers H, Specht F, Lucks JS. Cytotoxicity of magnetite-loaded polylactide, polylactide/glycolide particles and solid lipid nanoparticles. Int J Pharm. 1996;138(1):85-94. doi:10.1016/0378-5173(96)04539-5.

115. Sarmento B, Martins S, Ferreira D, Souto EB. Oral insulin delivery by means of solid lipid nanoparticles. Int J Nanomedicine. 2007;2(4):743-9.

116. Muller RH, Runge $S$, Ravelli V, Mehnert W, Thunemann AF, Souto EB. Oral bioavailability of cyclosporine: solid lipid nanoparticles (SLN) versus drug nanocrystals. Int J Pharm. 2006;317(1):82-9. doi:10.1016/j. ijpharm.2006.02.045.

117. Zhang N, Ping Q, Huang G, Xu W, Cheng Y, Han X. Lectin-modified solid lipid nanoparticles as carriers for oral administration of insulin. Int J Pharm. 2006;327(1-2):153-9. doi:10.1016/j.ijpharm.2006.07.026.
118. Liu J, Gong T, Wang C, Zhong Z, Zhang Z. Solid lipid nanoparticles loaded with insulin by sodium cholate-phosphatidylcholine-based mixed micelles: preparation and characterization. Int J Pharm. 2007;340(1-2):153-62. doi:10.1016/j.ijpharm.2007.03.009.

119. Zhang Z, Lv H, Zhou J. Novel solid lipid nanoparticles as carriers for oral administration of insulin. Pharmazie. 2009;64(9):574-8.

120. Zhang ZH, Zhang YL, Zhou JP, Lv HX. Solid lipid nanoparticles modified with stearic acid-octaarginine for oral administration of insulin. Int J Nanomedicine. 2012;7:3333-9. doi:10.2147/IJN.S31711ijn-7-3333.

121. Sarmento B, Mazzaglia D, Bonferoni MC, Neto AP, do Céu Monteiro M, Seabra V. Effect of chitosan coating in overcoming the phagocytosis of insulin loaded solid lipid nanoparticles by mononuclear phagocyte system. Carbohydr Polym. 2011;84(3):919-25. doi:10.1016/j. carbpol.2010.12.042.

122. Fonte P, Nogueira T, Gehm C, Ferreira D, Sarmento B. Chitosan-coated solid lipid nanoparticles enhance the oral absorption of insulin. Drug Deliv Transl Res. 2011;1(4):299-308. doi:10.1007/s13346-011-0023-5.

123. Yang R, Gao R, Li F, He H, Tang X. The influence of lipid characteristics on the formation, in vitro release, and in vivo absorption of protein-loaded SLN prepared by the double emulsion process. Drug Dev Ind Pharm. 2011;37(2):139-48. doi:10.3109/03639045.2010.497151.

124. Yang X, Liu Y, Liu C, Zhang N. Biodegradable solid lipid nanoparticle flocculates for pulmonary delivery of insulin. J Biomed Nanotechnol. 2012:8(5):834-42.

125. Knowles MR, Boucher RC. Mucus clearance as a primary innate defense mechanism for mammalian airways. J Clin Invest. 2002;109(5):571-7. doi:10.1172/JCl15217.

126. Lai SK, Wang YY, Hanes J. Mucus-penetrating nanoparticles for drug and gene delivery to mucosal tissues. Adv Drug Deliv Rev. 2009;61(2):15871. doi:10.1016/j.addr.2008.11.002

127. Kang SK, Woo JH, Kim MK, Woo SS, Choi JH, Lee HG, et al. Identification of a peptide sequence that improves transport of macromolecules across the intestinal mucosal barrier targeting goblet cells. J Biotechnol. 2008;135(2):210-6. doi:10.1016/j.jbiotec.2008.01.021.

128. Pridgen EM, Alexis F, Kuo TT, Levy-Nissenbaum E, Karnik R, Blumberg RS et al. Transepithelial transport of Fc-targeted nanoparticles by the neonatal Fc receptor for oral delivery. Sci Transl Med. 2013;5(213):213ra167213ra167. doi:10.1126/scitranslmed.3007049.

\section{Submit your next manuscript to BioMed Central and take full advantage of:}

- Convenient online submission

- Thorough peer review

- No space constraints or color figure charges

- Immediate publication on acceptance

- Inclusion in PubMed, CAS, Scopus and Google Scholar

- Research which is freely available for redistribution

Submit your manuscript at www.biomedcentral.com/submit
C Biomed Central 